\title{
EJNSO
}

\section{Microdebrider Intracapsular Tonsillectomy and Traditional Extracapsular Dissection Tonsillectomy in Children: A Comparative Study}

\author{
Mohammed M. Osman ${ }^{1}$, Mariam F. Tony ${ }^{2}$ and Ali R. Abd El-Hakim ${ }^{1}$ \\ ${ }^{1}$ Department of Otorhinolaryngology, Faculty of Medicine, Assiut University, \\ Assiut, Egypt, ${ }^{2}$ Department of Otorhinolaryngology, Hurghada General \\ Hospital, Red Sea, Egypt
}

\begin{abstract}
Objective: We planned to compare the outcome of the standard dissection tonsillectomy and microdebrider intracapsular tonsillectomy on the same patient to avoid confounders that may mask an actual association or, falsely establish an apparent association between the type of surgery and outcome when no actual association between them exists.

Patients and Methods: Thirty children with chronic tonsillitis, snoring and sleep apnea due to tonsillar hypertrophy were included in the study. One tonsil was removed using the microdebrider intracpsular method and the other side by the standard dissection technique. The two sides were compared for duration of surgery, intraoperative blood loss, need for bipolar cauterization and stitches, reactionary and secondary bleeding, pain, wound healing and recurrence.
\end{abstract}

Results: The operative time was significantly shorter in tonsillar sides performed with the microdebrider $(\mathrm{P}$-value $=0.02)$. The intraoperative bleeding and the need for using bipolar diathermy were more in microdebrider (P-value $<0.001$ and 0.03 , respectively). While the use of stitches was significantly higher with dissection technique $(\mathrm{P}$-value $=0.03)$. There was no difference regarding postoperative pain in the first day, but subsequently there was more pain among dissection side with significant difference (P-value $<0.001)$. Healing was significantly faster in microdebrider side (P-value $<0.001)$. Recurrence was detected among one side operated with the microdebrider with no significant difference between both sides $(\mathrm{P}$-value $=0.3)$.

Conclusion: Microdebrider intracapsular tonsillectomy is a safe and effective procedure in treating children with chronic tonsillitis and sleep apnea.

Keywords: Tonsillectomy, Microdebrider, Intracapsular, Extracapsular, Dissection

\section{Introduction}

Tonsillectomy is a widespread surgical procedure performed in children. Complete tonsillectomy has always been done in obstructive sleep apnea syndrome due to tonsillar hypertrophy ${ }^{1}$. Partial tonsillectomy or tonsillotomy is increasingly indicated in some cases attributed to tonsillar hypertrophy not infection, probably due to the introduction of a variety of antibiotics so many cases could be treated medically ${ }^{1-5}$.

Tonsillar hypertrophy is the most significant cause of obstructive sleep apnea in children often associated with malnutrition due to problems with swallowing. It also causes disturbance in behavior, cardiorespiratory and 
neurocognitive function ${ }^{6,7}$.

Several modifications of tonsillectomy procedures have been done along time concerning technique and instrumentation to reduce morbidity and get better outcome ${ }^{8}$. One of these techniques is the microdebrider intracapsular tonsillectomy which was described by many authors. This technique entails surgical removal of most of the tonsil without reaching its capsule. Surgeons believed that leaving a shielding layer of lymphoid tissue over the pharyngeal muscular and neurovascular structures prevents their damage, thereby reducing the severity and duration of postoperative pain ${ }^{9,10}$.

Intracapsular tonsillectomy provides a good option for young children with obstructive sleep apnea due to tonsillar hypertrophy, as it may reduce postoperative problems of extracapsular dissection tonsillectomy, including pain, lack of oral intake, subsequent dehydration, overnight hospitalization and delayed postoperative bleeding ${ }^{4,11}$.

Also, some authors encouraged resection of only the obstructive tonsillar tissue and leaving remnants in the tonsillar beds to preserve the protective immunological function of the tonsillar tissue ${ }^{5}$.

Microdebrider accomplishes removal of tonsillar tissue by trimming it from the lower pole medially to the upper pole laterally, to maintain the tonsillar capsule with a thin rim of tonsillar tissue 9,12 .

Several studies with conflicting results have compared the outcome of extracapsular and intracapsular tonsillectomy ${ }^{12-14}$. Several demographic and clinical factors as potential confounders that differ from a patient to another can bias the study results and lead to inaccurate conclusions ${ }^{15}$. Thus, our aim was to compare the outcome of the 2 types of surgeries on the same patient to avoid confounders that may mask an actual association or, more frequently, falsely establish an apparent association between the type of surgery and outcome when no actual association between them exists.

\section{Patients and Methods:}

The study was performed as a prospective, randomized controlled trial comparing the outcome of microdebrider intracapsular tonsillectomy and standard dissection tonsillectomy.

It was conducted as an internal control patient study (in which one tonsil was removed via microdebrider and the other via dissection). Patients collected from outpatient clinic, Assiut university hospital, were enrolled in this study during the period from February 2016 to April 2017. The study included thirty children (18 boys and 12 girls) aged 414 years; with the mean age $6 \pm 0.5$. Informed consent was taken from the guardians of patients after approval of the study by the ethical committee. Inclusion criteria included children (416 years) with chronic tonsillitis, snoring and sleep apnea due to tonsillar hypertrophy.

Exclusion criteria included patients with history of previous tonsillar or adenoid surgery, peritonsillar abscess, cleft lip/palate, tumors and systemic diseases. All patients underwent routine preoperative investigations for surgical fitness. They were given preoperative antibiotic (ampicillin $20 \mathrm{mg} / \mathrm{kg}$ body weight to a maximum of $1 \mathrm{gm}$ ).

The surgical procedure started with the patient in a standard Rose position. Induction and maintenance of general inhalational anesthesia was performed with sevoflurane. Orotracheal intubation was done. The right tonsil was removed using the microdebrider intracapsular method and the left side removed by the standard dissection technique.

As described by Bent at al., ${ }^{11}$, A Hurd retractor was used to medialize the tonsil 
while protecting the adjacent mucosa of the tonsillar pillars and the tongue base. Tonsils were shaved with the aid of Karl Storz, Unidrive S III ENT with SCB (Tuttlingen, Germany), with $40^{\circ}$ curved blade backward serrated cutting edge, in oscillation mode at $5000 \mathrm{rpm}$.

Tonsils were shaved from the inferior to superior pole; this aimed at preventing blood from obscuring visualization of the surgical field. Starting medially and proceeding laterally until the plane of the pillar was reached. When the plane of the pillars has been reached, it was helpful to stabilize and control the anterior pillar to maximize tissue removal and minimize injury to mucosa. A Hurd Elevator is used in these circumstances to retract the anterior pillar, medialize the remaining tonsil, and allow deeper portion of tonsillar tissue to be shaved. Dissection was carried down to but not through the capsule of the tonsil. If minor bleeding was observed at the end of procedure, bipolar cauterization was applied taking care to avoid thermal damage. If bleeding didn't stop, silk suturing was performed using size 1 silk suture.

For conventional dissection tonsillectomy, the mucosa of the anterior pillar was incised using curved blunt scissor over the upper pole, and the tonsillar capsule was identified. The tonsil was dissected along the capsule from superior to inferior pole using blunt dissector. The lower pole was ligated using a silk suture size 1 and the tonsil was cut with the cold scissors.

Hemostasis was achieved by ties and ligatures at superior and inferior poles using silk size 1 .

Pack was applied in the tonsillar fossa to control minimal bleeding. Bipolar diathermy was used if needed. If bleeding didn't stop, silk suturing was to be performed.

The time to perform each procedure was recorded intraoperatively. The intraoperative blood loss was also estimated by weighing the soaked packs and recording the volume of sucked blood. Also, the need for cauterization and stitching was assessed. Pain was evaluated based upon the pain faces scale (Fig. 1) ${ }^{16}$.

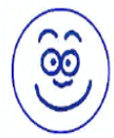

No Hurt

0

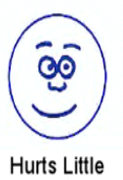

Bit
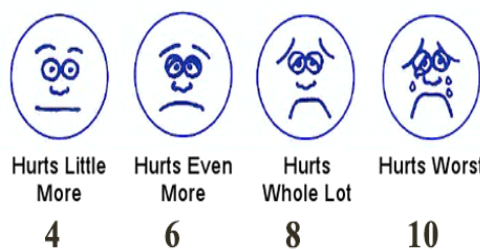

Figure (1) Wong-Baker FACES Pain Rating Scale

A seven-day outpatient course of amoxicillin dosed at $80 \mathrm{mg} / \mathrm{kg}$ body weight was given to all patients. Paracetamol $15 \mathrm{mg} / \mathrm{kg}$ body weight was prescribed every 6 hours after discharge from hospital.

Continuous monitoring of the patients after discharge was carried out by their parents.

Each patient was examined for a routine postoperative visit at the end of 1st, 2nd, 3rd weeks, and 1st, 3rd and 6th months. Comparison between both sides was done regarding pain, reactionary and secondary hemorrhage, wound healing, and recurrence.

\section{Statistical analysis:}

Results were expressed as mean \pm SD. SPSS V 16.0 was used for data analysis. Paired sample t-test was used for comparison between the 2 sides in all patients and for the qualitative data, Wilcoxon signed rank test was used for comparison. P-Value was considered significant if $<0.05$.

\section{Results:}

A summary of study results is demonstrated in table (1). Regarding the 
operative time, it was significantly shorter in tonsillar sides performed with the microdebrider $(\mathrm{P}$-value $=0.02)$ (fig. 2).

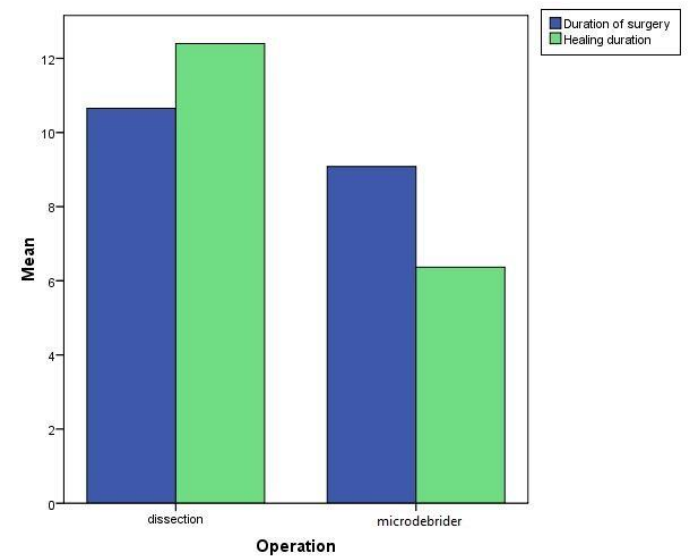

Figure (2): Duration of surgery and wound healing in tonsillar sides performed with dissection tonsillectomy and sides with microdebrider intracapsular tonsillectomy.

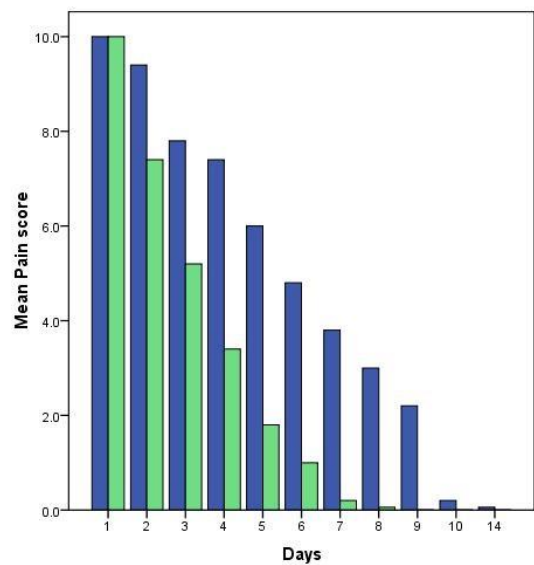

Figure (3): Pain in tonsillar sides performed with dissection tonsillectomy and sides with microdebrider intracapsular tonsillectomy

The intraoperative bleeding was more in microdebrider with high significance (P-value < 0.001). The need for using bipolar diathermy was significantly higher with microdebrider (P-value = 0.03). On the other hand, the use of stitches was significantly higher with dissection technique $(\mathrm{P}$-value $=0.03)$. There was no difference regarding postoperative pain in the 1st day, but subsequently there was more pain among dissection side with significant difference (P-value < 0.001) (fig. 3). Healing was significantly faster in microdebrider side $(\mathrm{P}$-value $<0.001)$ (fig. 2). Recurrence was detected among one of the sides operated with the microdebrider with no significant difference between both sides $(\mathrm{P}-\mathrm{value}=$ $0.3)$.

\section{Discussion :}

This study was performed as a prospective, randomized internal control patient trial comparing the outcome of microdebrider intracapsular tonsillectomy and standard dissection tonsillectomy: one tonsil was removed via microdebrider and the other via dissection).

We found a significant difference between the two techniques regarding the operative time which was shorter in case of microdebrider. This agrees with Mixon et al., ${ }^{17}$ and Wilson et al., ${ }^{18}$ in their studies comparing different techniques for tonsillectomy. They found that microdebrider partial tonsillectomy had significantly shorter operative time compared with other techniques. On the other hand, some authors $^{12,19,20}$ found no significant difference between the two groups regarding surgical time. However, the latter two studies used electrocautery instead of conventional dissection tonsillectomy. Conversely, Sobol et al., 13 found significantly shorter duration when using monopolar electrocautery, rather than microdebrider tonsillectomy.

Concerning the blood loss in the present study, there was more significant bleeding among the microdebrider group rather than the conventional group. This is in concordance with some authors ${ }^{13}$, 17, 20 who showed significantly higher blood loss with the microdebrider technique. This is probably due to the fact that bleeding caused by the use of microdebrider doesn't reveal the tissues clearly, especially the deeper tonsillar clefts, thereby jeopardizing pharyngeal musculature ${ }^{9}$. Alternatively, Koltai et al. ${ }^{2}$ and Derkay et al., ${ }^{19}$ showed no 
significant difference in blood loss between the two methods.

There was an increased tendency to use diathermy to stop bleeding in cases of microdebrider tonsillectomy, whereas stitches were applied more among dissection technique with statistical significance. Despite that; there was no significant postoperative bleeding among both groups. Also, there was no statistical difference between the two techniques, yet slightly higher in the dissection group. This is somewhat consistent with Sobol et al., ${ }^{13}$ who documented a delayed postoperative bleed in 1 patient in the electrocautery dissection tonsillectomy group. This is probably because traditional tonsillectomy removes the tonsil by dissection along the capsule, leaving the major feeding vessels exposed and susceptible to dehydration and inflammation postoperatively. On the reverse, the rate of delayed hemorrhage may be less with microdebrider tonsillectomy because the tonsillar capsules and the major feeding vessels are not reached.

Consequently, there was no need for readmission of any of the operated children in either group. This agrees with studies performed by Bent et al. ${ }^{11}$. Moreover, Koltai et al., ${ }^{2}$ also noted a lower rate of postoperative hemorrhage in intratonsillar microdebrider tonsillectomy patients compared with dissection tonsillectomy patients, without statistical significance.

Regarding wound healing, it was significantly faster in the microdebrider than dissection tonsillectomy. This agrees with many series $2,9,11,19,20$. In contrast, Gabr et al., ${ }^{12}$ detected no significant difference between the two groups.

Considering post tonsillectomy pain, in the first day, in the current study, it was the same in both groups. Later on, it was significantly more intense amongst the traditional dissection technique. This agrees with other studies $2,14,19,20$ who stated that partial tonsillectomy was associated with significantly less pain than total tonsillectomy during recovery.

A hypothetical complication of microdebrider tonsillectomy is tonsillar regrowth and the development of chronic tonsillitis. This is because this technique aims at decreasing the tonsillar size to the level of the capsule instead of removing the whole capsule. As a result, there is a possibility of leaving some tonsillar tissue, which may allow for regrowth and tonsillitis in the future. The rate of this complication with microdebrider in our study is approximately $3.3 \%$ which is equivalent to that reported by Sorin et al., ${ }^{20}$, and higher than the rate estimated by Solares et al., ${ }^{19}$ which is $0.5 \%$. This is probably due to the small sample size in our study.

Some studies have described obstructive symptoms due to tonsillar regrowth and recurrent tonsillitis over a longer period after microdebrider tonsillectomy ${ }^{5}$. Therefore, it is essential to assess different techniques broadly, focusing on immediate and late results. So comprehensive follow-up is a must to recognize symptomatic rehypertrophy.

\section{Conclusion:}

According to our study, microdebrider intracapsular tonsillectomy is a favorable procedure in treating children with tonsillitis and sleep apnea. We recommend it because of its safety, efficacy, minor pain, short duration and rapid healing apart of high intraoperative blood loss. 
Table (1): A comparison between the outcome of the standard dissection tonsillectomy and microdebrider intracapsular tonsillectomy in the study patients.

\begin{tabular}{|c|c|c|c|}
\hline Point of comparison & $\begin{array}{l}\text { Microdebrider } \\
(\mathrm{N}=30)\end{array}$ & $\begin{array}{l}\text { Dissection } \\
(\mathrm{N}=30)\end{array}$ & $P$-value \\
\hline Duration of surgery (minutes)* & $9.1 \pm 3$ & $10.7 \pm 3$ & 0.02 \\
\hline Intraoperative bleeding $(\mathrm{cc})^{*}$ & $31.6 \pm 11$ & $22.6 \pm 6$ & $<0.001$ \\
\hline Duration of healing (days)* & $6 \pm 1$ & $12 \pm 3$ & $<0.001$ \\
\hline Need for diathermy $* *$ & 13 & 7 & 0.03 \\
\hline Need for stitches $* *$ & 1 & 10 & 0.03 \\
\hline 1 stitch & - & 8 & \\
\hline 2 stitches & 1 & 2 & \\
\hline Reactionary bleeding** & 1 & 2 & 0.6 \\
\hline Secondary bleeding** & 0 & 0 & 1 \\
\hline $\begin{array}{l}\text { Pain at } 1^{\text {st }} \text { day } * * \\
10\end{array}$ & 30 & 30 & 1 \\
\hline $\begin{array}{l}\text { Pain at } 2^{\text {nd }} \text { day } * * \\
6 \\
8 \\
10\end{array}$ & $\begin{array}{c}9 \\
21 \\
-\end{array}$ & $\begin{array}{c}- \\
8 \\
22\end{array}$ & $<0.001$ \\
\hline $\begin{array}{l}\text { Pain at } 7^{\text {th }} \text { day } * * \\
0 \\
2 \\
4 \\
6\end{array}$ & $\begin{array}{l}28 \\
2 \\
- \\
-\end{array}$ & $\begin{array}{c}- \\
6 \\
21 \\
3\end{array}$ & $<0.001$ \\
\hline $\begin{array}{l}\text { Pain at } 10^{\text {th }} \text { day } * * \\
0 \\
2 \\
4\end{array}$ & $\begin{array}{c}30 \\
- \\
-\end{array}$ & $\begin{array}{c}12 \\
17 \\
1\end{array}$ & $<0.001$ \\
\hline $\begin{array}{l}\text { Pain at } 14^{\text {th }} \text { day } * * \\
0 \\
2 \\
4\end{array}$ & $\begin{array}{c}30 \\
- \\
-\end{array}$ & $\begin{array}{c}21 \\
9 \\
- \\
\end{array}$ & 0.003 \\
\hline Recurrence ** & 1 & 0 & 0.3 \\
\hline
\end{tabular}

$\mathrm{N}$ number of operated sides

*Results expressed as mean \pm standard deviation

** Results expressed as number of operated sides

Paired sample t-test (quantitative data), Wilcoxon signed test (qualitative data)

$P$-value significant if $<0.05$

Face pain rating scale: 0 no hurt, 2 hurts little bit, 4 hurts little more, 6 hurts even more, 8 hurts whole lot, 10 hurts worst 


\section{Reference:}

1. Densert O, Desai H, Eliasson A, Frederiksen L, Andersson D, Olaison J, Widmark C. Tonsillotomy in children with tonsillar hypertrophy. Acta Otolaryngol. 2001; 121(7):854-8.

2. Koltai PJ, Solares CA, Koempel JA, Hirose K, Abelson TI, Krakovitz PR, Chan J, Xu M, Mascha EJ. Intracapsular tonsillar reduction (partial tonsillectomy): reviving a historical procedure for obstructive sleep disordered breathing in children. Otolaryngol Head Neck Surg. 2003; 129(5):532-8.

3. Ross AT, Kazahaya K, Tom LW. Revisiting outpatient tonsillectomy in young children. Otolaryngol Head Neck Surg. 2003; 128:326331.

4. Anand A, Vilela RJ, Guarisco JL. Intracapsular versus standard tonsillectomy: review of literature. J La State Med Soc. 2005; 157(5):259-61

5. Eviatar E, Kessler A, Shlamkovitch N, Vaiman M, Zilber D, Gavriel $\mathrm{H}$. Tonsillectomy vs. partial tonsillectomy for OSAS in children--10 years post-surgery follow-up. Int $\mathbf{J}$ Pediatr Otorhinolaryngol. 2009; 73(5):637-40.

6. Gronau S, Fischer Y. Tonsillectomy.Laryngorhinootolo gie. 2005; 84(9):685-90.

7. Wood JM., Cho M., Carney AS. Role of subtotal tonsillectomy ('tonsillotomy') in children with sleep disordered breathing. J Laryngol Otol. 2014; 128 Suppl $1:$ S3-.

8. Koempel, JA, Solares CA, and Koltai PJ. The evolution of tonsil surgery and rethinking the surgical approach to obstructive sleepdisordered breathing in children. Journal of Laryngology and Otology. 2006; 120(12): 993-100

9. Koltai PJ, Solares CA, Mascha EJ, $\mathrm{Xu} \mathrm{M}$. Intracapsular partial tonsillectomy for tonsillar hypertrophy in children. Laryngoscope. 2002; 112(pt 2):1719

10. Timms MS, Temple RH. Coblation tonsillectomy: a double blind randomized controlled study. J Laryngol Otol. 2002; 116:450452.

11. Bent JP, April MM, Ward RF, Sorin A, Reilly B, Weiss G. Ambulatory Powered Intracapsular Tonsillectomy and Adenoidectomy in Children Younger Than 3 Years. Arch Otolaryngol Head Neck Surg. 2004; 130:1197-1200.

12. Gabr SI, Harhash KA, El Fouly MS, Kamel AA, Eldwebes MM. Microdebrider intracapsular tonsillotomy versus conventional extracapsular tonsillectomy. Egypt J Otolaryngol. 2014; 30:220-4

13. Sobol SE, Wetmore RF, Marsh RR, Stow J, Jacobs IN. Postoperative Recovery After Microdebrider Intracapsular or Monopolar Electrocautery Tonsillectomy. A Prospective, Randomized, Single-blinded Study. Arch Otolaryngol Head Neck Surg. 2006; 132(3):270-274.

14. Lister M, Cunningham M, Benjamin B, Williams M, Tirrell A, Schaumberg D. Microdebrider tonsillotomy vs electrosurgical tonsillectomy: a randomized, double-blind, paired control study of postoperative pain. Arch Otolaryngol Head Neck Surg. 2006; 132:599-604.

15. Skelly AC, Dettori JR, Brodt ED. Assessing bias: the importance of considering confounding. 
Evidence-based spine-care journal. 2012, 3(01): 9-12.

16. Wong D, Baker C. Pain in children: comparison of assessment scales. Pediatr Nurs. 1988; 14:9-17 .

17. Mixon C, Weinberger P, Austin M. Comparison of microdebrider subcapsular tonsillectomy to harmonic scalpel and electrocautery tonsillectomy. Am J Otolaryngol. 2007; 28:13-17.

18. Wilson YL, Merer DM, Moscatello AL. Comparison of three common tonsillectomy techniques: a prospective randomized. Laryngoscope. 2009; 119:162-170 .

19. Derkay C, Darrow D, Welch C, Sinacori J. Post-tonsillectomy morbidity and quality of life in pediatric patients with obstructive tonsils and adenoid: microdebrider vs electrocautery Otolaryngol Head Neck Surg. 2006; 134:114120.
20. Bitar MA, Rameh C. Microdebrider-assisted partial tonsillectomy: short and Longterm outcomes. Eur Arch Otorhinolaryngol. 2008; 265:459463.

21. Solares CA, Koempel JA, Hirose K, Abelson TI, Reilly JS, Cook SP, April MM, Ward RF, Bent JP, $\mathrm{Xu} \mathrm{M}$, Koltai PJ. Safety and efficacy of powered intracapsular tonsillectomy in children: a multicenter retrospective case series. Int J Pediatr Otorhinolaryngol. 2005; 69:21-26.

22. Sorin A, Bent JP, April MM, Ward RF. Complications of microdebrider-assisted powered intracapsular tonsillectomy and adenoidectomy. Laryngoscope. 2004; 114:297-300. 